\title{
Genetic variability of Bipolaris sorokiniana isolates using URP-PCR
}

\author{
Michele B. Mann ${ }^{1}$, Cristina C. Spadari ${ }^{1}$, Thaisa Feltrin ${ }^{1}$, Ana Paula G. Frazzon ${ }^{1}$, José Carlos Germani ${ }^{2} \&$ \\ Sueli T. Van Der Sand ${ }^{1}$
}

${ }^{1}$ Departamento de Microbiologia, Imunologia e Parasitologia, Instituto de Ciências Básicas da Saúde, Universidade Federal do Rio Grande do Sul (UFRGS), Rua Sarmento Leite 500, 90050-170, Porto Alegre, RS, Brazil; ${ }^{2}$ Departamento de Produção de Matéria Prima, Faculdade de Farmácia, UFRGS, Av. Ipiranga 2752, 90610-000, Porto Alegre, RS, Brazil

Author for correspondence: Sueli T. Van Der Sand, e-mail: svands@ufrgs.br

\begin{abstract}
Spot blotch disease, caused by Bipolaris sorokiniana, is one of the major diseases of wheat and is responsible for large losses of wheat crops worldwide. We used polymerase chain reaction (PCR) with universal rice primers (URP) for molecular characterization of 60 monosporic $B$. sorokiniana isolates from Brazil and other countries, and evaluated the diversity of the samples. PCR amplification generated 232 different DNA fragments ranging in size from 100 to $2018 \mathrm{bp}$. The primers URP-4R, URP-2R, and URP-1F generated greater numbers of amplified fragments $(36,30$, and 25 , respectively) from the single-spore isolates, and some diversity was observed among the isolates generated using these primers. The primers URP-2F, URP-6R, URP-17R, URP-30F, and URP-38F produced a pattern of monomorphic fragments and $73 \%$ of the isolates showed an average of 44 different DNA-amplified fragments. Primer URP-2F generated a 578-bp fragment that was common to $83.7 \%$ of the isolates; primer URP-6R generated a 548-bp fragment and primer URP-38F generated a 650 bp product that was common to $89.1 \%$ and $80 \%$ of the isolates, respectively. The URP-PCR primers provided important information about the genetic profiles of the monosporic cultures, which showed intraspecific variability among the monoconidial isolates and among the monosporic cultures that originated from the same polysporic strain. Our results indicate that URP's are sensitive and give reproducible results for assaying the genetic variability of $B$. sorokiniana.
\end{abstract}

Key words: Triticum aestivun, spot blotch disease, wheat.

\section{INTRODUCTION}

Wheat (Triticum aestivun L.) is one of the most important cereal grasses, used extensively as a raw material for food and beverages and on a smaller scale for animal fodder (Cunha \& Bacaltchuk, 2000). Although Brazil is a large producer of grains, it is not self-sufficient in wheat production and depends on imports to fully supply the domestic demand (USDA, 2013). In addition, several environmental factors affect wheat production in Brazil, including warm, humid winters that promote the development of fungal diseases that can result in up to $50 \%$ loss of winter crops.

Brazil and other warm humid countries are affected by spot blotch, which is caused by the fungus Bipolaris sorokiniana (Sacc. in Sorok) Shoemaker, 1959, (teleomorph): Cochliobolus sativus (Ito \& Kuribayashi) Drechsl. Ex Dastur. It is the causal agent of common root rot, leaf spot, seedling blight, head blight of wheat and barley and black point of grains and affects all parts of the plant. Sources of primary inoculum include infected seeds, remains of infected crops, volunteer plants, secondary hosts, and non-germinated conidia (Reis et al., 2001). The use of pathogen-free seeds is one strategy for reducing sources of inoculum and controlling the spread of disease.

Considering the damage caused by this fungus and the demonstrated variability in its genome, molecular characterization of $B$. sorokiniana is required to better understand its genetic variability. Molecular techniques including random amplified polymorphic DNA (RAPD) analysis (Oliveira et al., 2002; Müller et al., 2005; Jaiswal et al., 2007) and cleaved amplified polymorphic sequence (CAPS) analysis of the ITS regions have been used to characterize this pathogen (Nascimento \& Van Der Sand, 2008). Data reported in the literature show a high degree of intra- and inter-specific groupings (Müller et al., 2005). Studies of $B$. sorokiniana polymorphisms among isolates from different geographic origins have revealed a high degree of variability.

Polymerase chain reaction with universal rice primers (URP-PCR) has been used to study inter- and intraspecific genetic variability among microorganisms and has been shown to produce quick and effective results (Kang et al., 2002). Kang et al. (2003) used 20 URPs to study 25 isolates of six different Alternaria species that produced host-specific toxins; their results showed that eight primers could be used to reveal polymorphisms of 
Alternaria isolates at the intra- and inter-species levels. Cho et al. (2012), studying Pseudomonas pv. strains, found that the pathovar could be divided into four clusters based on $63 \%$ similarity by URP-PCR using $2 \mathrm{~F}, 9 \mathrm{~F}$, and $17 \mathrm{R}$ primers. The $P$. syringae pv. tomato cluster was also well separated from 30 other $P$. syringae pathovars.

Aggarwal et al. (2008) successfully characterized isolates of Chaetomiun spp. using URP-PCR. In contrast, in a study of $B$. sorokiniana isolates from India, Aggarwal et al. (2010) observed a polymorphic profile among the isolates and only two URP-PCR primers were able to amplify monomorphic bands in this phytopathogen. The aim of the present study was to assess the genetic diversity of monoconidial isolates of $B$. sorokiniana using URP-PCR assays.

\section{MATERIALS AND METHODS}

\section{Fungal cultures}

Twenty B. sorokiniana isolates used in this study were isolated from wheat seeds supplied by Embrapa Trigo (Brazil) and International Maize and Wheat Improvement Center (CIMMYT) (Mexico) (Table 1).

\section{Monoconidial cultures}

The monoconidial cultures were obtained from the aerial mycelia of the 20 polyconidial cultures grown on plates with potato dextrose agar (PDA). A $0.85 \%$ saline solution was poured over the plated colonies, and the conidia were transferred to microcentrifuge tubes. The tubes were vortexed thoroughly to achieve complete conidia release. The suspension was transferred to a Petri dish with PDA and incubated at room temperature for $2 \mathrm{~h}$. Using a stereomicroscope with optical magnification of $\times 40$, the conidia were transferred using a needle to slant tubes with PDA media. The tubes were maintained at $24 \pm 2^{\circ} \mathrm{C}$ until the complete colonies had developed, and then were stored at $4^{\circ} \mathrm{C}$. Each spore culture was designated with a letter (A, $\mathrm{B}$, and $\mathrm{C}) ; 60$ monoconidial cultures comprised the isolates used in this work.

\section{Morphological characteristics of the colonies}

Morphological groupings were made based on colonial characteristics and mycelial growth (Jaiswal et al., 2007). For this purpose, a $0.5 \mathrm{~cm}$ disc containing mycelium of each isolate was inoculated in the center of a Petri dish with PDA medium and incubated at $25^{\circ} \mathrm{C}$ for $5 \mathrm{~d}$ with a $12 \mathrm{~h}$ photoperiod. The morphological analysis consisted of observation of mycelial color and texture, formation or lack of formation of sectors, and type of mycelial growth.

\section{Genomic DNA extraction}

Genomic DNA was extracted following the protocol developed by Ashktorab \& Cohen (1992) with some modifications. The isolates were grown in Erlenmeyer flasks containing $300 \mathrm{~mL}$ potato-dextrose broth (PD). After inoculation, incubation took place at room temperature under orbital agitation (Oxylab) of $120 \mathrm{rpm}$ for 7-10 days in order to obtain $300 \mathrm{mg}$ of mycelia (wet weight). After incubation, the mycelium of each isolate was strained and washed three times with sterile distilled water, and excess water was removed using filter paper. Weighed mycelium was ground to fine powder using liquid nitrogen. The powder was transferred to a tube, and $1 \mathrm{~mL}$ of extractionlysis buffer (200 mM Tris-HCl pH 8.0, $250 \mathrm{mM} \mathrm{NaCl}, 25$ mM EDTA, 2\% SDS) per gram of mycelium was added along with $10 \mu \mathrm{L} / \mathrm{mL} \beta$-mercaptoethanol (Sigma) and 50 $\mu \mathrm{g} / \mathrm{mL}$ proteinase $\mathrm{K}$ (Promega). The tubes were incubated

TABLE 1 - Origin of Bipolaris sorokiniana isolated from wheat seeds.

\begin{tabular}{lcl}
\hline \hline Number & Isolate code & \multicolumn{1}{c}{ City, State, Country } \\
\hline 1 & 98030 & Cruz Alta, Rio Grande do Sul, Brazil \\
2 & 98011 & Lagoa Vermelha, Rio Grande do Sul, Brazil \\
3 & 98012 & Lagoa Vermelha, Rio Grande do Sul, Brazil \\
4 & 98043 & Pelotas, Rio Grande do Sul, Brazil \\
5 & 98026 & Piratini, Rio Grande do Sul, Brazil \\
6 & 98032 & Engenheiro Beltrão, Paraná, Brazil \\
7 & 98017 & Samambaia, Paraná, Brazil \\
8 & 98013 & União da Vitória, Paraná, Brazil \\
9 & 98023 & União da Vitória, Paraná, Brazil \\
10 & 98034 & União da Vitória, Paraná, Brazil \\
11 & 98041 & União da Vitória, Paraná, Brazil \\
12 & BS15M2 & Delicias, Chihuahua, Mexico \\
13 & BS16M1 & Delicias, Chihuahua, Mexico \\
14 & BS18M2 & Poza Rica, Veracruz, Mexico \\
16 & CM0105 & Poza Rica, Mexico \\
17 & BS52M1 & Monterrey, Nuevo León, Mexico \\
18 & CS1004 & Hanoi, Vietnam \\
19 & NRRL 5851 & South Africa \\
\hline 10 & CF0201 & South Africa \\
\hline
\end{tabular}


in a water bath at $65^{\circ} \mathrm{C}$ for $1 \mathrm{~h}$, shaken every $15 \mathrm{~min}$, and then centrifuged at $2795 \times g$ for $20 \mathrm{~min}$. The supernatant was transferred to clean centrifuge tubes and DNA was purified twice with 1 volume of phenol ( $\mathrm{pH} \mathrm{8.0)}$ and three times with 1 volume of phenol-chloroform $(1: 1 \mathrm{v} / \mathrm{v})$. Finally, 1 volume of chloroform/isoamyl alcohol $(24: 1 \mathrm{v} / \mathrm{v})$ was added to the supernatant. Pancreatic RNAse I $(50 \mu \mathrm{g} / \mathrm{mL})$ was added to the aqueous phase resulting from the centrifugation and the mixture was incubated at $37^{\circ} \mathrm{C}$ for $20 \mathrm{~min}$. DNA was precipitated with 0.1 volume of $3 \mathrm{M}$ sodium acetate and 2.5 volumes of isopropanol at $-20^{\circ} \mathrm{C}$. DNA was collected with a glass rod, transferred to a falcon tube, washed with $70 \%$ ethanol $(\mathrm{v} / \mathrm{v})$, and centrifuged at $2795 \times \mathrm{g}$ for $10 \mathrm{~min}$. DNA was allowed to dry at room temperature and was then resuspended in Milli-Q water and stored at $-20^{\circ} \mathrm{C}$.

\section{DNA amplification by URP-PCR}

DNA from the 60 single spore isolates was amplified using 12 URP primers (Table 2), as described by Kang et al. (2002) with modifications. The reactions were performed in a $25 \mu \mathrm{L}$ volume containing $50 \mathrm{ng}$ of genomic DNA, $1 \mathrm{U}$ Taq DNA polymerase, $20 \mathrm{pmoL}$ primer, $0.2 \mathrm{mM}$ dNTP, $1 \times$ reaction buffer, $4 \mathrm{mM} \mathrm{MgCl}_{2}, 200 \mathrm{ng} / \mu \mathrm{L}$ bovine serum albumin, and sterile Milli-Q water. The amplification conditions were adapted accordingly to the samples used in this work to obtain the optimal products. All amplifications were performed in an Eppendorf Mastercycler Personal thermal cycler under the following conditions: one cycle of denaturation at $94^{\circ} \mathrm{C}$ for $4 \mathrm{~min}$ followed by 35 cycles of denaturation at $94^{\circ} \mathrm{C}$ for $1 \mathrm{~min}$, annealing at $55^{\circ} \mathrm{C}$ for $1 \mathrm{~min}$ and at $72^{\circ} \mathrm{C}$ for $2 \mathrm{~min}$, and a final extension at $72^{\circ} \mathrm{C}$ for $7 \mathrm{~min}$. Amplification products were separated by electrophoresis in $1.5 \%(\mathrm{w} / \mathrm{v})$ agarose gel, stained with ethidium bromide, and photographed under UV light using a Vilber Lourmat Doc-Print II. Digital photos of the gels were taken using a Kodak DC 120 digital camera and Kodak 1D (version 3.5.2) software. All amplifications were repeated at least twice for each isolate in separate experiments.

\section{Statistical analysis}

The amplifications of all the isolates obtained with the 12 URP primers were used to construct a binary matrix by scoring the presence and absence of fragments as 1 as 0 , respectively. The matrix was analyzed using PAST using Jaccard's coefficient of similarity. The dendrogram was produced using the unweighted pair-group method with arithmetic averages (UPMGA). The data sets were considered clustered if they had a similarity coefficient above $70 \%$. All amplifications were repeated at least twice for each isolate in separate experiments.

\section{RESULTS}

The single-spore isolates grown in PDA medium showed phenotypic variation in mycelia color, from gray to black and beige. This variability was observed among $75 \%$ of the isolates. Among single-spore isolates that originated from the same polysporic culture this variability was also observed.

Each of the 12 tested primers was efficient in producing different levels of polymorphism. The 232 polymorphic fragments produced by the primers varied in size from 100 to $2018 \mathrm{bp}$. The 12 primers amplified 84\% of the isolates. The primer URP-30F amplified $95 \%$ of the isolates and primer URP-13R showed amplification products in $70 \%$ of the isolates. Primers URP-1F, URP-2R, and URP-4R produced a greater number of polymorphic fragments than primers URP-2F, URP-6R, URP-9F, URP13R, URP-17R, URP-25F, URP-30F, URP-32F, and URP38F (Table 3).

Primer URP-2F was more specific to amplify isolates from Brazil while primer URP-6R was able to distinguish isolates from international collections, producing distinct amplification profiles among isolates. However, none of the other primers was able to discriminate the geographic origins of the isolates. Polymorphic fragments from singlespore isolates that originated from the same polysporic strain were observed with all the primers. This polymorphism is shown in Figure 1 for some of the isolates amplified with primer URP-1F. Primers URP-2F, URP-6R, and URP$38 \mathrm{~F}$ showed some monomorphic fragments among the isolates they amplified. Primer URP-2F generated a 578 bp fragment in $83.7 \%$ of the isolates, primer URP-6R produced a fragment of $548 \mathrm{bp}$ in $89.1 \%$ of the isolates, and primer URP-38F showed a $650 \mathrm{bp}$ amplification product in $80 \%$ of the isolates. Figure 2 shows the profile of the isolates amplified using primer URP-38F. The dendrogram constructed from these data revealed 23 groups, assuming a similarity coefficient of $>70 \%$. Using primer URP-38F it was possible to group some of the single-spore isolates that originated from the same polysporic strain from Brazil and also with some from international strains. Conidia A, B, and C of isolate 98043 from Pelotas (Brazil), and conidia A and B of isolate 98030 from Cruz Alta (Brazil) clustered together with a similarity coefficient of 1.000 . Conidia B and $\mathrm{C}$ of isolate 98011 clustered together with a similarity coefficient of 1.000. In contrast, isolates 98013A, 98013C, 98034B, 98034C, 98023A, 98023B, 98023C, 98041A, 98041B, 98041C and 98032B and C from Paraná (Brazil) showed a very low similarity coefficient. Isolate $98017 \mathrm{C}$ did not group with any other isolate. Isolates 98032A, 98034A, 98012B, 98011A, BS52M1A, and BS52M1B did not amplify with primer URP-38F.

The data obtained with isolates from international collections using primer URP-38F showed that isolates BS18M2, BS16M1, A20, and their conidia A, B, and C clustered together with a similarity coefficient of 1.000 . On the other hand, conidia A, B, and C of isolates NRRL5851 and CF0201 from South Africa did not cluster together, and showed a very low similarity coefficient (Figure 2). This primer can be used to study variability among 
M.B. Mann et al.
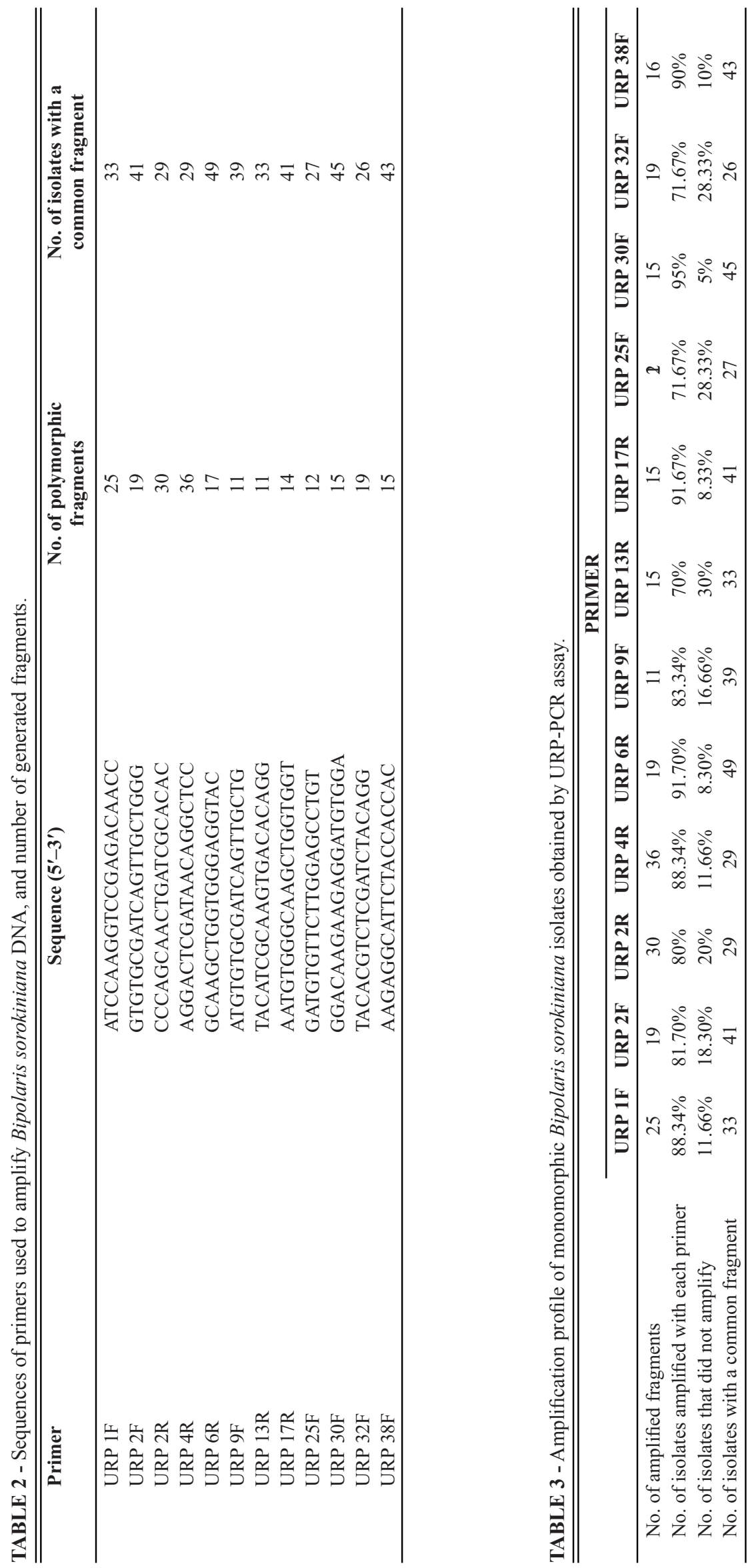


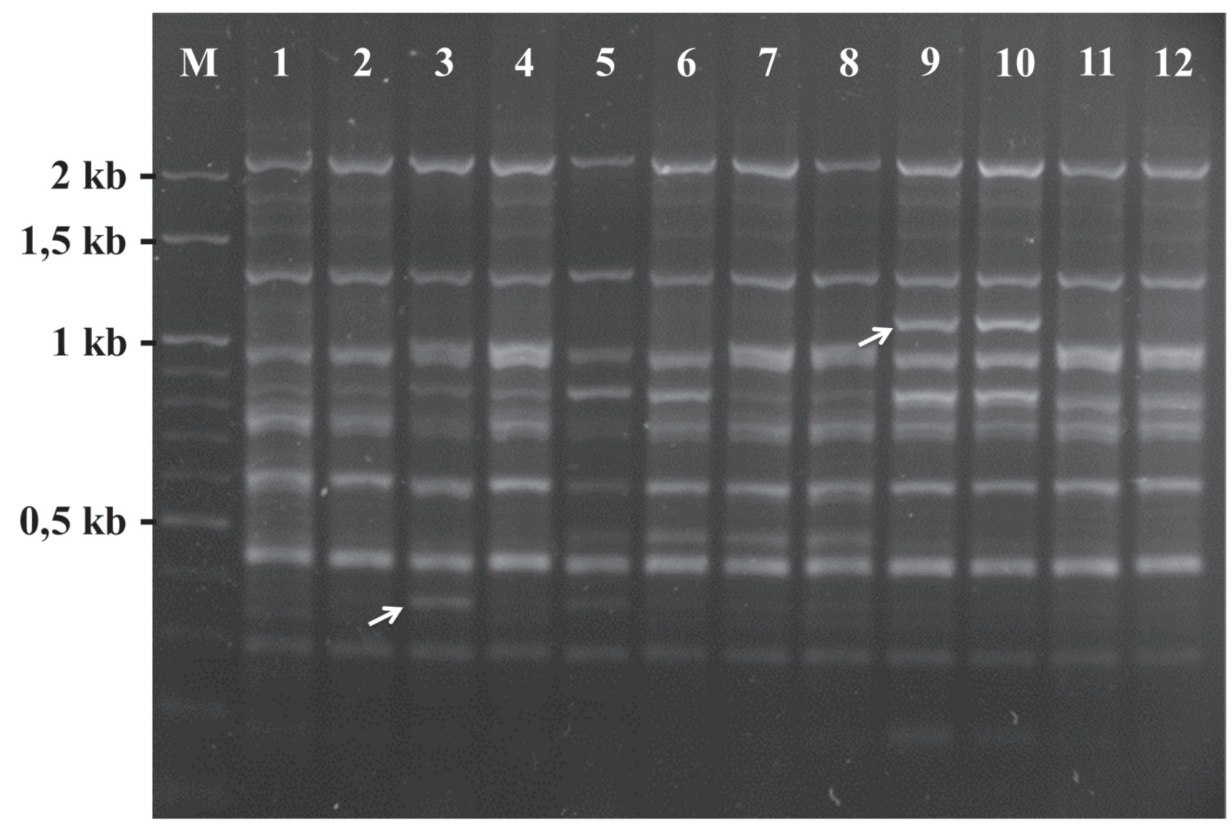

FIGURE 1 - Genomic DNA amplification product of Bipolaris sorokiniana monosporic isolates obtained using primer URP-1F. M, DNA Marker Ladder 100 bp; 1, 98013A; 2, 98013B; 3, 98026B; 4, 98026C; 5, 98032B; 6, 98032C; 7, 98034B; 8, 98034C; 9, 98041A; 10, 98041C; 11, BS16M1A; 12, BS16M1C. $\rightarrow$ indicates polymorphism among the isolates. the isolates however it is not a good primer to study the geographic origin of the isolates. Primer URP-4R generated the highest number of polymorphic fragments among the amplified isolates. The dendrogram (Figure 3) show the polymorphisms that resulted from this amplification, where few isolates showed a similarity coefficient of 1.000 . The dendrogram constructed with the amplification data obtained with primer URP-4R showed 34 groups with a similarity coefficient $>70 \%$. The $98043 \mathrm{~A}-\mathrm{B}$ isolates from Brazil confirmed the previous grouping of URP-38F isolates and BS15M2A isolates (Delicias, Chihuahua, Mexico) with URP-4R isolates in the dendrogram. Isolates 98011A, 98012B, 98012C, 98030A, 98032B, and 98034A-C were not amplified with primer URP-4R.

\section{DISCUSSION}

The molecular characterization of single-spore isolates of $B$. sorokiniana revealed wide diversity in their genetic profiles. This work demonstrates the applicability of URP-PCR primers to the study of $B$. sorokiniana isolates; URP-PCR can be used for characterization and evaluation of intraspecific polymorphisms of monosporic fungal cultures.

Poloni et al. (2008) evaluated morphological variability of monosporic and polysporic B. sorokiniana cultures grown in different media, and observed high rates of morphological variability in the replicates of polysporic cultures but few differences among monoconidial cultures. In the present study we observed high genetic diversity and some morphological variability among isolates: in most groups containing the three monosporic isolates, at least one of the isolates showed high variability and consequently a low similarity coefficient.

Christensen (1925) working with B. sorokiniana isolates also observed very important morphological, physiological and biochemical variability among the isolates when grown in dextrose potato agar. Tinline (1961) proposed that mutation, heterokaryose and hybridization would increase the possibility of variability among the isolates.

Jaiswal et al. (2007) studied monoconidial cultures of $B$. sorokiniana isolated from wheat-growing regions in India and showed high morphological variability between the isolates, which formed distinct morphological groups; these researchers also observed more polymorphic than monomorphic fragments in the RAPD assay. Similarly, in the present study, high variability was observed in the amplification profiles and a greater number of polymorphic than monomorphic fragments were obtained. Although the amplification products of some of the monosporic isolate groups showed the same profiles, the presence of variable patterns was more common. One explanation for this variability might be the multinucleated conditions of B. sorokiniana mycelial cells and conidia, in which heterokaryosis can lead to mitotic recombination that may contribute to the DNA polymorphisms detected in this pathogen (Müller et al. 2005). When we analyzed some of the resulting groupings among isolates obtained with primers URP-38F and URP-4R, some clustering among isolates from Brazil and Mexico was apparent. So, we can suggest that these two primers can be used to access genetic diversity. This information is applicable to epidemiologic studies examining the mechanism of introduction or 


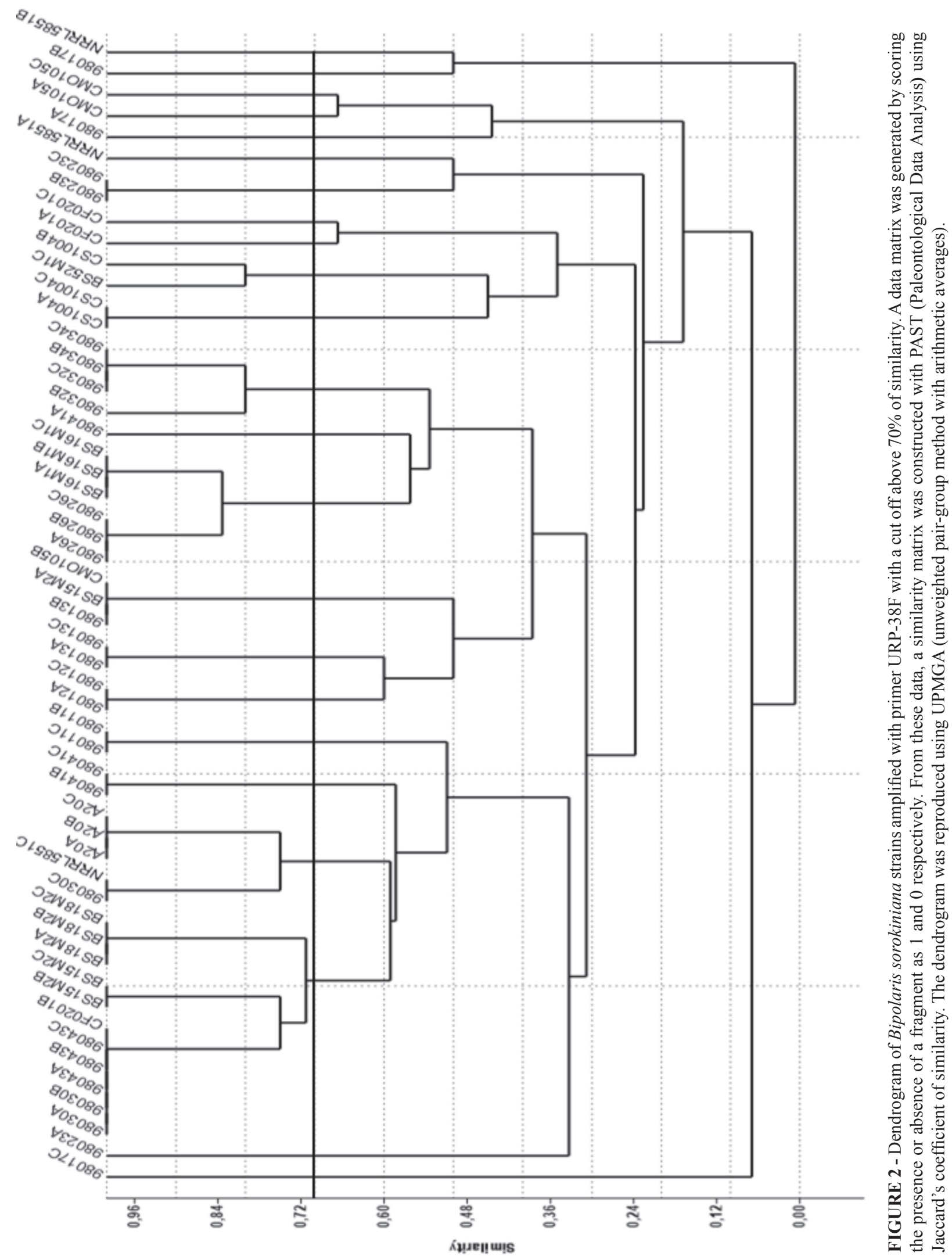




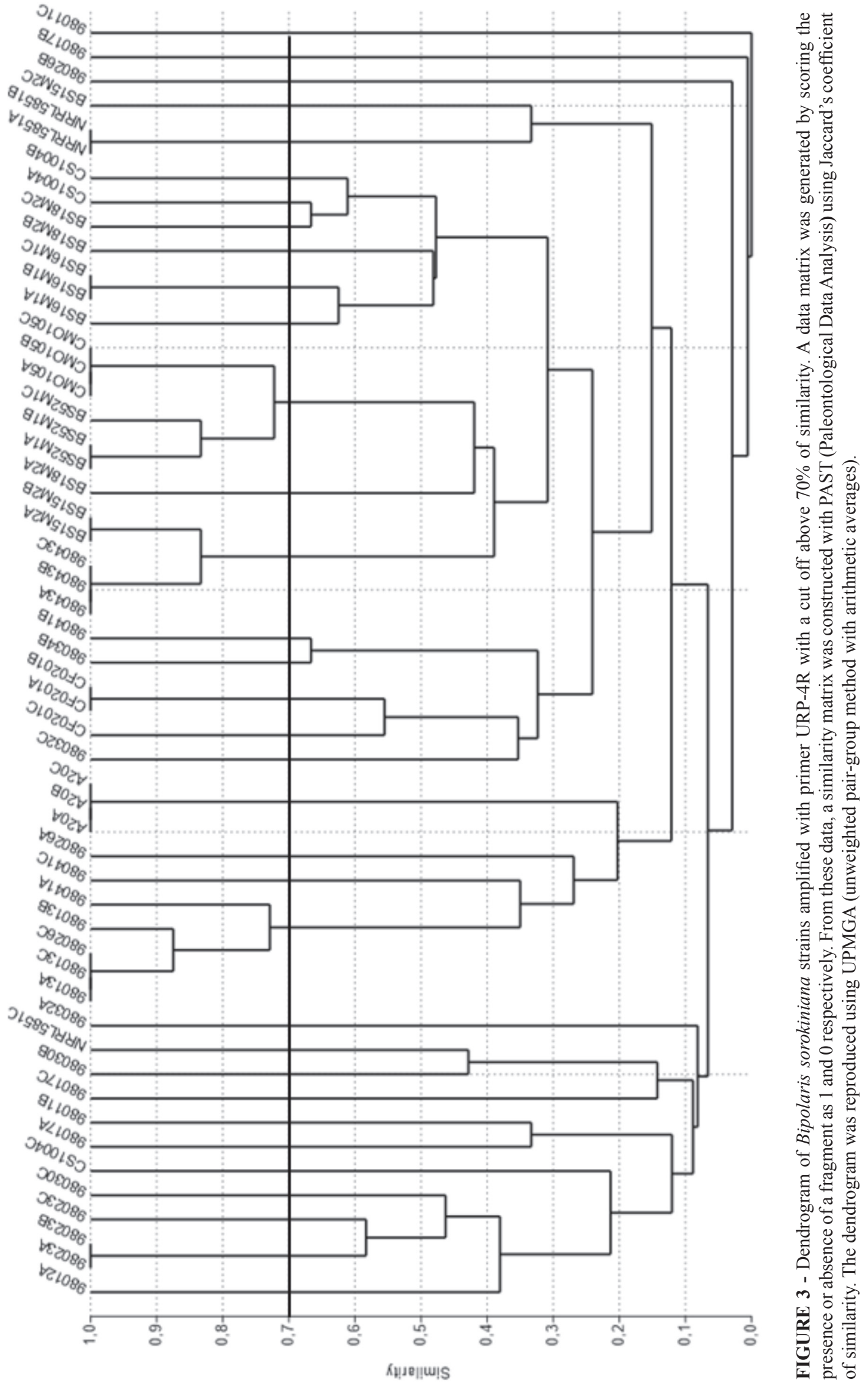


gene flow of B. sorokiniana among distinct geographical regions.

The same 12 URP-PCR primers as used in the present study were used to characterize of $B$. sorokiniana from India; only two of these primers failed to produce amplification products and one primer produced monomorphic fragments that could be used as molecular markers (Aggarwal et al., 2010). Here, we observed that isolates from Brazil were more efficiently amplified with URP primers and different behavior was observed in isolates from other countries. It was not possible to group the isolates according to geographical region. Using RAPD, Oliveira et al. (2002) and Müller et al. (2005) observed high levels of genetic variability among isolates from Brazil, suggesting high rates of polymorphism. Nascimento \& Van Der Sand (2008) analyzed polymorphism of ITS regions of $B$. sorokiniana rDNA using PCR-RFLP, and observed great diversity among isolates from different regions and countries. In that study, the authors were able to separate isolates from Brazil from those of the other countries, but isolates could not be geographically separated at within-country scales (Nascimento \& Van Der Sand, 2008). Zhong \& Steffenson (2001) assessed the genetic diversity of Cochhliobolus sativus based on virulence and AFLP markers and found no correlation between genetic similarity and geographic origin.

In contrast, Aggarwal et al. (2010) correlated URPPCR data with the geographic origin of the isolates. In our studies, URP primers were also shown to be conserved in fungi, enabling detection of intraspecific variation among sets of single-spore isolates derived from the same polysporic strain. We observed that Brazilian isolates showed higher genetic diversity than isolates from other countries, which had little genetic similarity to those from Brazil. A similar finding was reported by Nascimento \& Van Der Sand (2008), who examined genotypic variability of $B$. sorokiniana by PCR-RFLP analysis using rDNA from polysporic strains. Kang et al. (2003) demonstrated that eight URP primers could be used to detect inter- and intraspecific polymorphisms among 25 isolates of six Alternaria species, and obtained results that allowed the isolates to be grouped according to their geographical regions.

In the present study, the URP primers 13R, 25F, and $32 \mathrm{~F}$ amplified smaller number of genomic DNA fragments in monosporic isolates. According to Aggarwal et al. (2008), these same primers failed to amplify the genomic DNA of Chaetomium spp., suggesting low genetic homology with this pathogen. The genetic variability could be attributed to interactions between genes and environmental conditions such as climatic differences among the geographic areas from where isolates are collected. In this study the diversity observed among single spore $B$. sorokiniana isolates using the URP primers might be a result of many factors such as population dynamics, gene flow, mutations, and the multinuclear nature of conidia, which can lead to high polymorphism. Gene flow is especially important in relation to plant pathogens in agroecosystems because it is the process that introduces new genes into agricultural fields distant from the site of the original mutation what could be one of the reasons to explain why some isolates from Brazil cluster with isolates from Mexico. Further work must be done on the genetic characterization of $B$. sorokiniana isolates and then the identification of the pathogen will be more fast and accurate.

The results obtained with URP-PCR in the present study enabled a fast and efficient variability analysis for $B$. sorokiniana. The monosporic isolates examined in this study showed very high genomic diversity. The profiles generated from the URP-PCR results difference among the monosporic isolates from each other and also among the isolates derived from the same polysporic strains. The dendrogram analysis showed higher diversity for isolates from Brazil, compared to isolates from international collections.

\section{ACKNOWLEDGEMENTS}

We are grateful to Julie Nicol, Monica Mezzalama, Etienne Duveiller and Henri Maraite (CIMMYT) and Kerry O'Donnel (USDA) for kindly providing the Bipolaris sorokiniana samples from the other countries, and to Airano Prestes from Embrapa for providing the $B$. sorokiniana isolates from wheat seeds from Brazil. We also thank Conselho Nacional de Desenvolvimento Científico e Tecnológico - CNPq for scholarships. This study was financed by Coordenação de Aperfeiçoamento de Pessoal de Nível Superior - CAPES/PROF.

\section{REFERENCES}

Aggarwal R, Sharma V, Kharbikar LL, Renu S (2008) Molecular characterization of Chaetomium species using URP-PCR. Genetics and Molecular Biology 31:943-946.

Aggarwal R, Singh VB, Shukla R, Gurjar MS, Gupta S, Sharma TR (2010) URP-based DNA fingerprinting of Bipolaris sorokiniana isolates causing spot blotch of wheat. Journal of Phytopathology 158:210-216.

Ashktorab H, Cohen RJ (1992) Facile isolation of genomic DNA from filamentous fungi. Biotechniques 13:198-200.

Cho MS, Park DS, Yun YH, Kim SH, Shim MY, Choi CW, Kim YS (2012) Genetic differentiation of Pseudomonas syringae pathovar tomato from other $P$. syringae pathovars using REP-PCR and URP-PCR. Plant Pathology Journal 28:60-67.

Christensen JJ (1925) Physiologic specialization and mutation in Helminthosporium sativum. Phytopathology 15:785-795.

Cunha GR, Bacaltchuk B (2000) Tecnologia para produzir trigo no Rio Grande do Sul. Passo Fundo, RS. Embrapa Trigo.

Jaiswal SK, Sweta, Prasad LC, Sharma S, Kumar S, Prasad R, Pandey SP, Chand R, Joshi AK (2007) Identification of molecular marker and aggressiveness for different groups of Bipolaris sorokiniana isolates causing sport blotch disease in wheat (Triticum aestivun L.). Current Microbiology 55:135-141. 
Kang HW, Park DS, Go SJ, Eun MY (2002) Fingerprinting of diverse genomes using PCR with universal rice primers generated from repetitive sequence of Korean weedy rice. Molecules and Cells 13:281-287.

Kang HW, Lee BR, Yu SH (2003) Analysis of genetic relatedness in Alternaria species producing host specific toxins by PCR polymorphism. Plant Pathology Journal 19:221-226.

Kim JH, Lee WH, Ryu YJ, Cheong SS, Choi JS (2002) Analysis of genetic relationship and cultural characterization of Penicillium species isolated from postharvest decay of pear by random amplified polymorphic DNA. Korean Journal of Mycology 30:7885.

Müller MVG, Germani JC, Van Der Sand ST (2005) The use of RAPD to characterize Bipolaris sorokiniana isolates. Genetics and Molecular Biology 4:642-652.

Nascimento EJM, Van Der Sand ST (2008) Restriction analysis of the amplified ribosomal DNA spacers ITS1 and ITS2 of Bipolaris sorokiniana isolates. World Journal of Microbiology and Biotechnology 24:647-652.

Oliveira ARM, Prestes AM, Matsumura ATS, Van Der Sand ST (2002) Intraspecific variability of Bipolaris sorokiniana isolates determined by random-amplified polymorphic DNA (RAPD). Genetic and Molecular Research 1:350-358.
Poloni A, Müller MV, Pessi I, Van Der Sand ST (2008) Análise da variabilidade morfológica e taxa de crescimento de culturas policonidiais e monoconidias de Bipolaris sorokiniana. Biociências 16:52-63.

Reis EM, Carmona M (2001) Avaliação do potencial de rendimento de lavouras de trigo com vistas ao controle econômico de doenças foliares com fungicidas. 3 ed. Passo Fundo, RS. UPF.

Seo GS, Kim BR, Park MS, Kim MK, Yu SH (2002) Morphological characterization and URP-PCR analysis of Hypocrea sp., a weed mould of oyster mushroom cultivation. Korean Journal of Medical Mycology 3:86-94.

Sivanesan A (1990) Mycosphaerella graminicola. CMI Descriptions of Pathogenic Fungi and Bacteria $N^{\circ} 986$. Mycopathologia 109:51-53.

USDA (2013) United States Department of Agriculture - World agricultural supply and demand estimates. Available at: http:// www.usda.gov/oce/commodity/wasde/latest.pdf. Accessed on August 12, 2013.

Tinline RD (1961) Cochliobolus sativus: IV Drug resistant, color and nutritionally exacting mutants. Canadian Journal of Botany 39:1695-1704.

Zhong S, Steffenson BJ (2001) Virulence and molecular diversity in Cochliobolus sativus. Phytopathology 91:469-76. 